\title{
An interdisciplinary treatment approach of a unilateral cleft lip and palate adult: A case report.
}

\author{
Rajesh Murugan Ramachandra ${ }^{1}$, Manjula WS ${ }^{1}$, Kannan MS ${ }^{1}$, Nithya Murugan ${ }^{2}$ \\ ${ }^{1}$ Sree Balaji Dental College and Hospital, Chennai \\ ${ }^{2}$ General Dentist, Chennai
}

\begin{abstract}
An adult female patient, age 36 years, with a mild convex profile, operated unilateral cleft lip and palate (UCLP), severe crowded upper anterior, partially edentulous was referred for orthodontic treatment. After a detailed review of her pretreatment records, both surgical and non-surgical treatment plans were presented to the patient, who opted for a non-surgical interdisciplinary approach. Patient's 3-dimensional malocclusion required decrowding and derotation of upper anterior, periodontal and prosthodontics consultations and treatment. In addition to comprehensive orthodontic therapy, MBT (McLaughlin, Bennett, and Trevisi) prescription $0.022 \times 0.028$ "appliances were used to level, align and to establish a Class I relationship". After the orthodontic treatment, a combined periodontal and prosthodontics approach was used to enhance the patients esthetic and functional outcomes. The treatment goals of establishing proper occlusion, normal function, better esthetics, and a stable relationship was achieved. The purpose of this clinical case presentation is to demonstrate that an interdisciplinary treatment approach can significantly improve the transverse and antero-posterior discrepancies and achieve a satisfactory occlusion with a balanced soft tissue profile in adult patients with UCLP.
\end{abstract}

Keywords: Cleft lip and palate, Orthodontic treatment, Interdisciplinary approach, Adult patient.

Accepted on January 10th, 2019

\section{Introduction}

Patient with complex problems like-pathological migration of teeth, severe anterior proclination and molar mesial inclination due to localized aggressive periodontitis, missing teeth and tooth with pathology are treated by an interdisciplinary approach method. Interdisciplinary approach is more common for patients with mutilated dentition. The role of orthodontist in such an interdisciplinary treatment approach can be of primary or secondary depending on patient's need [1-4].

Primary role is, in a case wherein, an orthodontic patient requires other adjunctive specialty treatment. Secondary role, as in case where the orthodontic treatment rendered is an adjunct to other treatment planned. For example like in the case of space creation or tooth up righting to facilitate prosthetic replacement of missing teeth [5-7].

\section{Diagnosis and Etiology}

An adult South Indian female patient (age 36 years and 9 months) came to the Department of Orthodontics and Orthopedics of Sree Balaji Dental College and Hospital, Bharath University for orthodontic evaluation, by the reference from Department of Prosthodontics, for her severely rotated maxillary anterior tooth and mesially inclined lower posterior teeth. Patient's chief complaint, was the un-esthetic appearance of her face. She was born with non-syndromic left unilateral cleft lip and palate. Patient had a history of surgery done for her UCLP at an early age, but does not have any previous records. Patient also had a history of periodontal regenerative therapy, 3 years back in the same institution. Loss of incisal stop due to severely rotated maxillary left central incisor, lead to mobility of lower anterior which were later removed. (Figure 1a and b)

The panoramic radiograph showed endodontic treatment of mandibular canine, right first and second molars and also revealed generalized, moderate, bone loss [7-10].

\section{Treatment Objectives}

Goals of the treatment were to establish a more balanced soft tissue profile. Dentally, the goals were to derotate the maxillary left central incisor, level and align the dental arches and enhance the intercuspation. To achieve these objectives, the following treatment was planned [11-13].

1. A 0.022 slot MBT appliance was used to initially align the dental arches.

2. Mesially in and distally out maxillary left central incisor (1800 rotation) would be derotated.

3. Fixed prosthesis for lower anterior (both central and lateral incisors) would be placed after the orthodontic treatment.

4. Retention would be needed.

J Clin Dentistry Oral Health 2019 Volume 3 Issue 1 

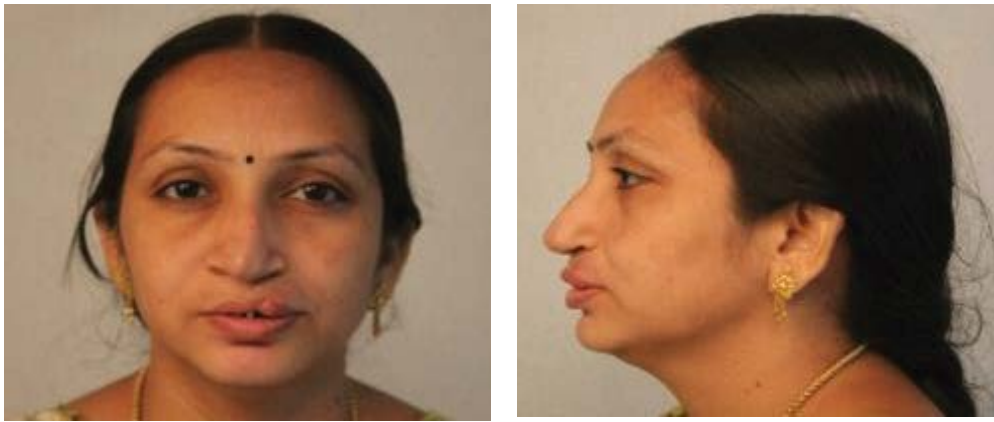

Figure 1(a). Pre-Treatment-Extra Oral.

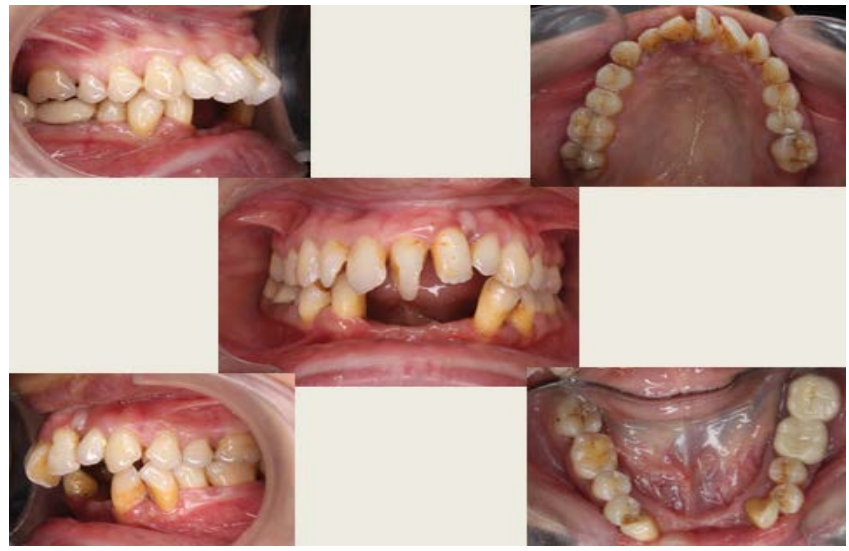

Figure 1(b). Pre-Treatment- Intra Oral.

\section{Treatment Alternatives}

The treatment of correcting the severely rotated maxillary left central incisor is by camouflaging with endodontic treatment, i.e., zirconium crown, was presented to the patient, but she declined. The risk of derotating periodontally compromised tooth, particularly loss of attachment and devitalisation, were discussed with the patient to provide complete informed consent [14].

\section{Treatment Progress}

After the diagnosis was completed, a treatment plan was developed, using a team approach with members from periodontics, endodontics, prosthodontics, and orthodontics. The initial plan involved periodontal disease treatment. Fullmouth and root planning were performed in 2 appointments. Endodontic treatment done in mandibular canines, first and second molars.

Orthodontic therapy included de-rotation of maxillary left central incisor and up-righting the mandibular canines and premolars to maintain edentulous space for prosthesis [1517].

The orthodontic treatment took approximately 10 months. After treatment of derotation and space maintaining, prosthesis were placed.

\section{Discussion}

The treatment for a cleft patient is challenging because of the difficulties underlying like malformed bone, dental abnormalities, necessity of interdisciplinary involvement and the need for excellent patient cooperation. Several orthodontic approaches are available to de-rotate maxillary anterior. It can be done by: power chain-over rotation tie, piggy-back and ligature tie. For this patient, a fixed appliance with MBT prescription was chosen for initial leveling and aligning. Because of rotated maxillary left central incisor, a Begg's central incisor bracket was bonded. Over rotation tie is given with power chain (closed) engaging bracket from the mesial in side towards the distal out and wraps around the tooth to engage the right central, lateral incisor and canine with light forces. Slight extrusion of the tooth is seen as it derotates which is corrected by piggy-back tie. As the rotation almost gets corrected, Begg's bracket is replaced by MBT bracket. For the de-rotation, it took about two months' time [18-20].

Initial leveling and alignment was achieved with 0.016 in NiTi archwire. $0.017 \times 0.025$ in NiTi archwire. $0.017 \times 0.025$ in S.S arches wire (Figure 2).

Proper expression of tip and torque were achieved with $0.019 \times 0.025$ in S.S arch wire. In mandibular arch, it results in up righting of canine and premolars which leads to maintenance of edentulous space for replacement of prosthesis, after the orthodontic treatment.

A number of studies have demonstrated that orthodontic treatment can improve the periodontal situation in UCLP patients by providing good function and improved esthetics after alignment. Tooth rotation and intrusion in our patient 
not only reduced the potential for trauma to these teeth, but also improved the gingival relationship.

Since mandibular right and left canine had a good root structure with moderate alveolar bone support, prosthodontist decided to use them as abutment tooth for prosthetic bridge placement. Adequate dental alignment and leveling, as well as maxillary and mandibular midline symmetry were also established. This successful interdisciplinary treatment improved patient's masticatory function, speech and smile esthetics.

After achieving proper balanced functional esthetics, post- operative OPG radiograph was done. As satisfactory tip and torque achieved, the patient was referred to the Department of Prosthodontics, without debonding of brackets from both the arches $[21,22]$ (Figure 3a and b).

\section{Conclusion}

Our case report describes the challenges in the treatment of adult UCLP patient. The proposed objectives of normal function such as speech, masticatory function, and better esthetics were achieved by interdisciplinary treatment. Although the maxillary left central incisor showed severe rotation before treatment, good result was achieved by the labial orthodontic treatment

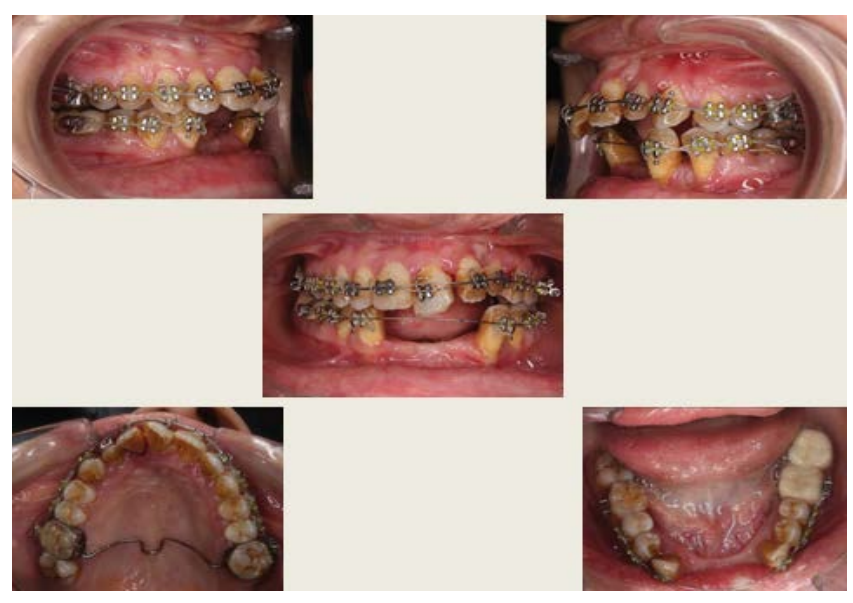

Figure 2. Mid-Treatment-Intra Oral.

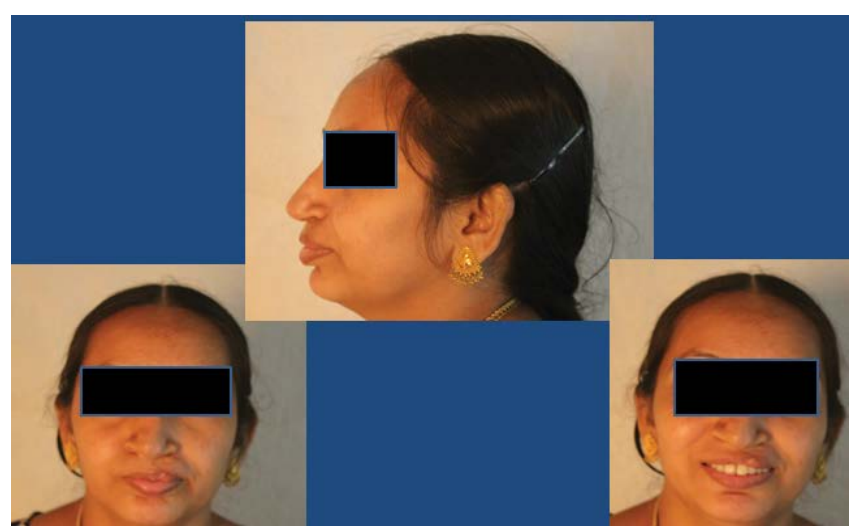

Figure 3(a). Post Treatment- Extra Oral.

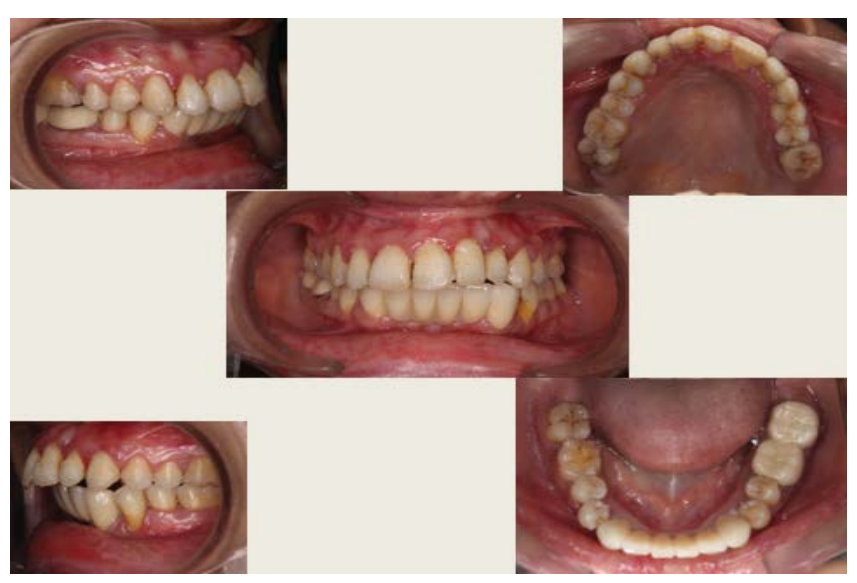

Figure 3(b). Post Treatment - Intra Oral.

J Clin Dentistry Oral Health 2019 Volume 3 Issue 1 
Citation: Ramachandra RM, Manjula WS, Kannan MS, et al. An interdisciplinary treatment approach of a unilateral cleft lip and palate adult: A case report. J Clin Dentistry Oral Health. 2018;3(1):1-4.

and the edentulous space management by prosthodontist with Zirconium Bridge showed good stability and pronunciation. Constant interaction between the team members and the patient, at all level of treatment are the key to success of interdisciplinary treatment approach.

\section{References}

1. Ma QL, Conley RS, Wu T, et al. Interdisciplinary treatment for an adult with a unilateral cleft lip and palate. Am J Orthod Dentofacial Orthop. 2014;146(2):238-48.

2. Tae KC, Gong SG, Min SK, et al. Use of distraction osteogenesis in cleft palate patients. Angle Orthod. 2003;73(5):602-7.

3. Yatabe MS, Garib DG, Janson G, et al. Is the presence of Simonart's band in patients with complete unilateral cleft lip and palate associated with the prevalence of missing maxillary lateral incisors? Am J Orthod Dentofacial Orthop. 2013;144(5):649-53.

4. Kokai S, Fukuyama E, Sato Y, et al. Comprehensive treatment approach for bilateral cleft lip and palate in an adult with premaxillary osteotomy, tooth autotransplantation, and 2-jaw surgery. Am J Orthod Dentofacial Orthop. 2015;147(1):114-26.

5. Olin WH. Cleft lip and palate rehabilitation. Am J Orthod Dentofacial Orthop. 1966;52(2):126-44.

6. Li W, Lin J. Dental arch width stability after quadhelix and edgewise treatment in complete unilateral cleft lip and palate. Angle Orthod. 2007;77(6):1067-72.

7. Kerr MP, Welch CD, Moore RN, et al. Functional regulator therapy for cleft palate patients. Am J Orthod Dentofacial Orthop. 1981;80(5):508-24.

8. Pierce GW, Terwilliger KF, Pennisi V, et al. Early orthodontic treatment in cleft palate children. Angle Orthod. 1956;26(2):110-20.

9. Germec-Cakan D, Canter HI, Cakan U, et al. Interdisciplinary treatment of a patient with bilateral cleft lip and palate and congenitally missing and transposed teeth. Am J Orthod Dentofacial Orthop. 2014;145(3):381-92.

10. Turpin DL. Interdisciplinary care leads the way. Am J Orthod Dentofacial Orthop. 2001;119:335.
11. Taner TU, Germec D, Er N, et al. Interdisciplinary treatment of an adult patient with old extraction sites. Angle Orthod. 2006;76(6):1066-73.

12. Moller KT, Austin CDS. Cleft Palate: Interdisciplinary issues and treatment for clinicians by clinicians. Am J Orthod Dentofacial Orthop. 1993;105(6):613-4.

13. Prahl-Andersena B, Ju Q. Quality Improvement of Cleft Lip and Palate Treatment. Angle Orthod. 2006;76(2):265-8.

14. Murray JC. Gene/environment causes of cleft lip and/or palate. Clin Genet. 2002;61(4):248-56.

15. Dentino KM, Peck S, Garib DG. Is missing maxillary lateral incisor in complete cleft lip and palate a product of genetics or local environment? Angle Orthod. 2012;82(6):959-63.

16. Mossey PA, Little J, Munger RG, et al. Cleft lip and palate. Lancet. 2009;374(9703):1773-85.

17. Ma QL, Conley RS, Wu T, et al. Interdisciplinary treatment for an adult with a unilateral cleft lip and palate. Am J Orthod Dentofacial Orthop. 2014;146(2):238-48.

18. Germec-Cakan D, Canter HI, Cakan U, et al. Interdisciplinary treatment of a patient with bilateral cleft lip and palate and congenitally missing and transposed teeth. Am J Orthod Dentofacial Orthop. 2014;145(3):381-92.

19. Brown S, Duncan D, Grant C, et al. Management of children with cleft lip and palate: A review describing the application of multidisciplinary team working in this condition based upon the experiences of a regional cleft lip and palate centre in the United Kingdom. Fetal Matern Med Rev 2005;16:1-27.

20. Li W, Lin J. Dental arch width stability after quadhelix and edgewise treatment in complete unilateral cleft lip and palate. Angle Orthod. 2007;77(6):1067-72.

21. Salyer KE, Rozen SM, Genecov ER, et al. Unilateral Cleft Lip-Approach and Technique. Semin Plast Surg. 2005;19(4):313-28.

22. Doddamani S, Patil RA, Nerli S. Multidisciplinary approach for improving esthetics in cleft palate and alveolus patient: A clinical report. J Indian Prosthodont Soc. $2005 ; 5(1): 39-42$.

\section{*Correspondence to:}

Rajesh Murugan Ramchandran

Sree Balaji Dental College and Hospital

Chennai, India

Tel: 9841124950

E-mail: drrajeshmurugan@gmail.com 